\title{
On the Control Process of Odor Material by Using Coffee Wastes
}

\author{
Eun Ji Woo, Yu Jin Oh, Ji Ye Yoo, and Chan Jin Park
}

\begin{abstract}
In this study, we investigated the current status of atmospheric environment with a variety of materials on the central of various environmental installments which are located in S-Free Economic Zone, Incheon. We were able to confirm that occurrence rate of Acetaldehyde is the most high among odor materials. Thus we tried to find characteristics of Acetaldehyde in odor emitting facility and the solutions that can increase efficiency of removal. In particular, Acetaldehyde indicates high efficiency in general treatment processing, however the minimum sensible concentration is very low and indicates the high rate at the level of contribution in odors. Accordingly, we proposed to estimate processing efficiency of existing activated carbon by making activated carbon that is included coffee wastes.
\end{abstract}

Index Terms-Acetaldehyde, coffee waste, activated carbon.

\section{INTRODUCTION}

In S-Free Economic Zone, Incheon, there is a variety of industrial facilities emitting atmospheric pollution and in particular, the odor problems are occurred constantly. In main odor emitting facility, there is sewage treatment plant, incineration facility of residential wastes, food and drink resource recovery plant and collection facility of food garbage. The living accommodations are concentrated around the main odor emitting facility and local residents are getting damaged by the odor. In these facilities, the occurrence amount of Aldehyde type was significantly low among designated odor materials [1]. We tried to find the method of increasing processing efficiency more than existing activated carbon as the method of increasing processing efficiency on these materials are requested. Accordingly, we estimated processing efficiency of odor materials by making activated carbon with coffee wastes based on study purpose. Current consumption level of coffee in Korea is very high as the top of the world. On the other hands, the amount of coffee wastes is getting increased. Coffee wastes are occurred after brewing coffee. $0.2 \%$ of the

Manuscript received August 30, 2016; revised November 9, 2016. Thi work was supported by Korea Ministry of environment as Knowledge-based environmental service Human resource development Project.

E. J. Woo is with the Department of Environment and Energy Engineering, Incheon National University, Incheon, Republic of Korea (e-mail: wej5366@ inu.ac.kr).

Y. J. Oh is with the Department of Environmental Health, Korea National Open University, Incheon, Republic of Korea (e-mail: jin220645@naver.com)

J. Y. Yoo is with the Department of Climate International Cooperation, Incheon National University, Republic of Korea (e-mail: yoojiye@inu.ac.kr).

C. J. Park is with the Department of Energy and Env. Engineering and the Department of Climate International Cooperation, Incheon National University, Republic of Korea (e-mail: cjpark@inu.ac.kr). coffee wastes were used to brew coffee and the rest of $99.8 \%$ is thrown out as coffee wastes [2]. For every year, approximately 27,000 tons of coffee wastes are getting thrown out but it is contributed to greenhouse gas emission after it is sorted as residential wastes but not food wastes [3]. Currently people attempt to use recyclable materials or energy source by utilizing coffee grounds in accordance with it. Coffee wastes is known as deodorizing effects and easily found, therefore it is expected to be effective in economics In precedent study using existing coffee wastes, we estimated also adaptability of odor processing by precedent studies to learn the efficiency of heavy metals removal.

\section{Methods}

First, we will investigate occurrence characteristics and current status about sample gas Acetaldehyde, coffee wastes characteristics, current status of practical use and precedent studies. Next, we will estimate propriety and expectation effectiveness of processing odor after making materials with activated carbon.

\section{CONTENTS}

\section{A. Current Status of Odor Facilities around Schools}

Currently large-scale industrial complex development is settled down including environmental foundational facilities on the central of school zone. The main odor emitting facilities are sewage treatment plant, incineration facility for residential wastes, food resource recovery plant and food garbage collection facility, showing in Fig. 1. In addition, residential developments are concentrated around these facilities. For regional characteristics, it is located around the sea closely therefore the weather is often foggy and odor problems are very severe not only the problem of climate.

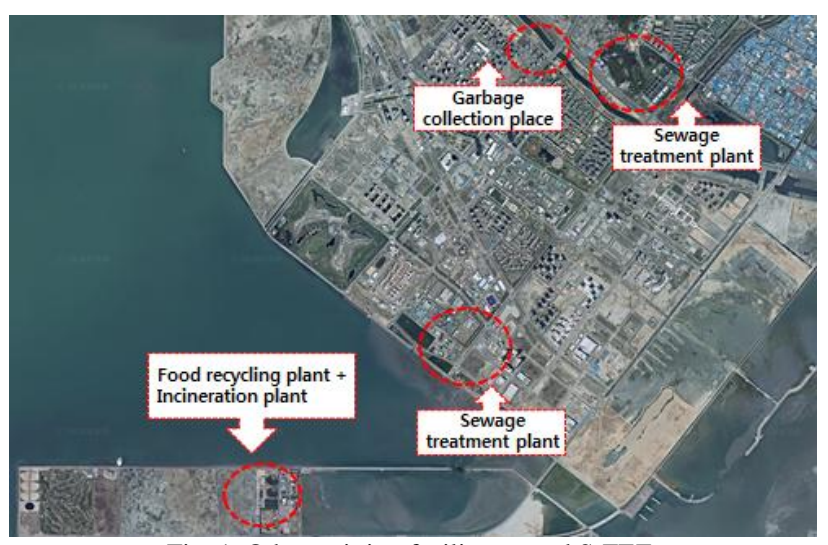

Fig. 1. Odor emitting facility around S-FEZ. 


\section{B. Odor Emitting and Current Status}

We investigated the main odor emitting place and found; sewage treatment plant, residential and food garbage disposal site and incineration. Accordingly, we selected complex odor, sulfur compounds and Aldehydes to investigate about the main odor emitting places.

According to the findings of the first half of 2016 year(see the Table I), discharge concentration value of complex odor, sulfur compounds and Aldehydes in most of facilities, was not largely exceeded on the standard of discharge. However we were able to confirm that discharge concentration was measured as higher rate than acceptable standards in particular facility and each odor. According to the result of the investigation on odor emitting zone of each odor facility, the frequency of odor emitting was high in sewage treatment plant due to sulfur compounds mostly. Particularly, we examined the improvement of processing process is required if sulfur compounds are not removed in the process of chemical treatment during the sewage processing process, otherwise the concentration of odor will be getting higher.

Residential waste collection facilities are very close to the residential areas, therefore a special odor treatment is required, however it was measured that the complex odor concentration is 100 300 times higher due to insufficient administration. In addition, discharge concentration of Acetaldehyde was approximately 11times higher than acceptable standard therefore intensive treatment is required [4]. Similar propensities were found also in other facilities and it is considered to be the first place where should be treated for odor control facility.

TABLE I: ODOR TEST RESULTS OF THE S-FREE ECONOMIC ZONE

\begin{tabular}{|c|c|c|c|c|c|c|}
\hline \multirow[b]{2}{*}{ Separation } & \multicolumn{3}{|c|}{2015} & \multicolumn{3}{|c|}{2016 (Average value) } \\
\hline & $\begin{array}{c}\text { Complex } \\
\text { Odor } \\
\text { (times) }\end{array}$ & $\begin{array}{l}\text { Sulfur } \\
\text { compounds } \\
(p p m)\end{array}$ & $\begin{array}{l}\text { Aldehydes } \\
\text { (ppm) }\end{array}$ & $\begin{array}{c}\text { Complex } \\
\text { Odor } \\
\text { (times) }\end{array}$ & $\begin{array}{l}\text { Sulfur } \\
\text { compounds } \\
(\text { ppm })\end{array}$ & $\begin{array}{l}\text { Aldehydes } \\
\text { (ppm) }\end{array}$ \\
\hline $\begin{array}{c}\text { "A" } \\
\text { Sewage treatment }\end{array}$ & $\begin{array}{l}144 \sim \\
3,000\end{array}$ & $\begin{array}{l}\mathrm{ND} \sim \\
18.9\end{array}$ & $\begin{array}{l}\mathrm{ND} \sim \\
0.15\end{array}$ & 439 & 0.22 & 0.006 \\
\hline $\begin{array}{c}\text { Garbage } \\
\text { collection place }\end{array}$ & 1,000 & $\begin{array}{l}\text { ND } \\
0.004\end{array}$ & $\begin{array}{l}0.006 \\
\sim 0.73\end{array}$ & 130 & 0.01 & 0.60 \\
\hline $\begin{array}{c}\text { "C" } \\
\text { Sewage treatment }\end{array}$ & 1,000 & $\begin{array}{l}\mathrm{ND} \sim \\
1.28\end{array}$ & $\begin{array}{l}\mathrm{ND} \sim \\
0.03\end{array}$ & 830 & 1.00 & 0.001 \\
\hline $\begin{array}{c}\text { "D" } \\
\text { Sewage treatment }\end{array}$ & 1,000 & $\begin{array}{l}\mathrm{ND} \sim \\
1.65\end{array}$ & $\begin{array}{l}\mathrm{ND} \sim \\
0.12\end{array}$ & 301 & 0.42 & 0.006 \\
\hline $\begin{array}{c}\begin{array}{c}\text { Incineration } \\
\text { plant }\end{array} \\
\end{array}$ & 100 & ND & $\begin{array}{l}\mathrm{ND} \sim \\
0.68\end{array}$ & 100 & 0.01 & 0.004 \\
\hline $\begin{array}{c}\text { Food recycling } \\
\text { plant }\end{array}$ & 10,000 & $\begin{array}{l}\mathrm{ND} \sim \\
0.08\end{array}$ & $\begin{array}{l}\mathrm{ND} \sim \\
0.35\end{array}$ & 610 & 0.23 & 0.64 \\
\hline
\end{tabular}

[Source: Korea Environment Corporation, Incheon Institute of Health Environment]

\section{The Occurrence of Acetaldehyde and Current Status of Process}

We selected Acetaldehyde as the main odor substance. Acetaldehyde is colorless gas and has volatility. It has also unique and bad odor. It smells like sour and rotting food. The processing efficiency is high in odor processing process comparatively because it dissolves easily in water. However the minimum concentration sensor is very low, $0.0015 \mathrm{ppmv}$ therefore odor emitting level of contribution is high and it became the problem. Acetaldehyde is occurred in most of industrial companies but particularly highly occurred in food manufacturer, food and residential food garbage facility. When harmful acetaldehyde is exposed for a short time, symptoms such as headache, nausea, chest pain, difficulty in breathing and sleepiness may be occurred. It is known that loss of direction sense and cancer may be occurred when it is exposed for a long time. Acetaldehyde is highly efficient in most of processing process including physical and chemical feathers, however the concentration was detected in the site highly and it became a problem. In the site, the management of odor control facility is very insufficient due to economical reasons therefore the improvement of odor control facility is required. Considering characteristics of Acetaldehyde, proper methods are required.

\section{Current Status and Feathers of Coffee Wastes in Domestic}

Since 2000s, the consumption of coffee in South Korea has been very increased. As shown in Fig. 2, compared to the consumption of coffee, domestic production is very low therefore South Korea is importing coffee over hundreds of thousands tons from United States, Brazil and Colombia mainly. Therefore it is considered that the amount of coffee wastes that is to be thrown out for one year is similar to this [5].

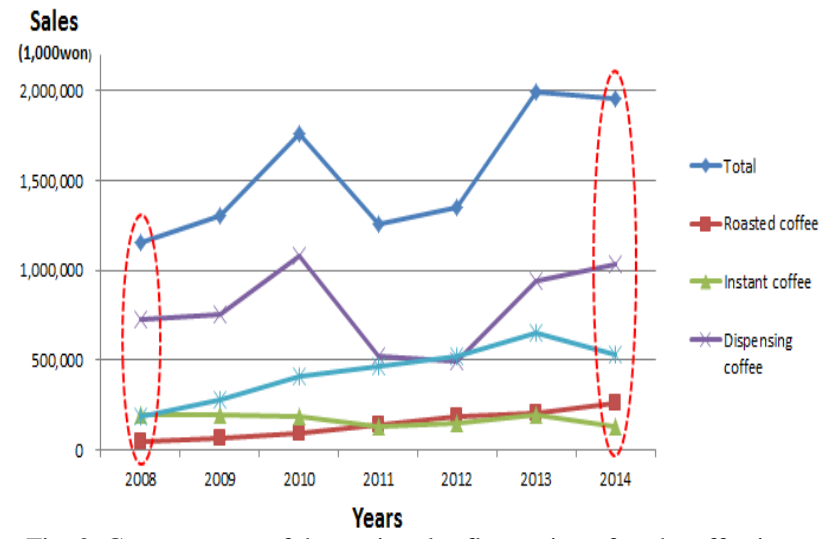

Fig. 2. Current status of domestic sales fluctuation of each coffee item [Source: http://stat.me.go.kr]

Coffee is made by grinding the coffee beans and roasting it. To brew coffee, the coffee beans are $0.2 \%$ used out of the total amount and the rest of it will be thrown. Coffee wastes that will be thrown out are classified into residential waste 
but not food garbage. For one year, approximately 27 million tons coffee grounds are thrown out and it is greatly related to the amount of green gas emission which is the main culprit of the global warming. On this wise, the environmental problem of coffee grounds became on the rise and as the amount of coffee wastes that is to be thrown out has been increased, many people attempts to recycle coffee wastes. In addition, coffee grounds are easily found in the coffee shop. Therefore many people recycle coffee grounds and create a new product and it is being used as deodorant and compost.

\section{E. Current Status of Studies Using Coffee Wastes}

There are many possibilities rose using coffee wastes and many studies has been conducted in order to prove the effectiveness of coffee wastes. Coffee has peculiar scent and it is recognized as good scent by most of people. It is also reported that coffee grounds may be efficient for deodorization. However, the most of study relative with coffee wastes are related with efficiency of heavy metal removal, therefore a few study materials about efficiency of odor treatment has reported.

In a recent study, it is estimated adsorptive power of thrown coffee wastes to liquid organic pollutant. After drying thrown coffee wastes and carbonizing, it was made as activated carbon. At this time, the adsorptive power of carbonized coffee was estimated in certain temperature condition by differentiating the carbonizing temperature, and as a result, it was efficient in activated carbon coffee at higher temperature [6].

In a study regarding adsorption characteristics by making activated carbon and using coffee wastes, coffee wastes were changed into coffee wastes. The adsorption characteristics were measured by analyzing the carbonation of the activated carbon in more detail. In this study, we were able to confirm that the adsorption power of activated coffee grounds is very great by comparison of dried coffee wastes, carbonized coffee wastes and activated coffee wastes. The pictures below show the SEM analysis and pore of dried coffee wastes carbonized coffee wastes and activated coffee wastes from the above. As shown in Fig. 3, pore is regarded as important factor which increase the efficiency of activated carbon and difference can be found according to each processing process [7].

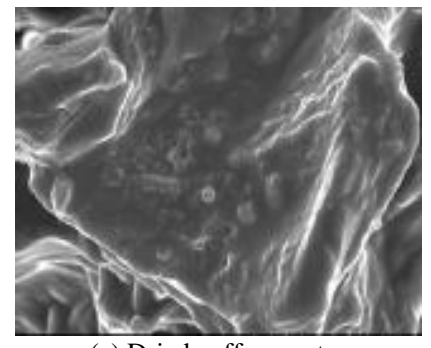

(a) Dried coffee wastes

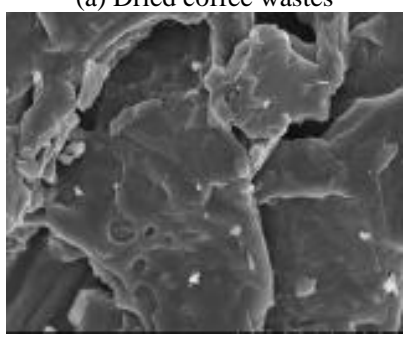

(b) Carbonized coffee wastes

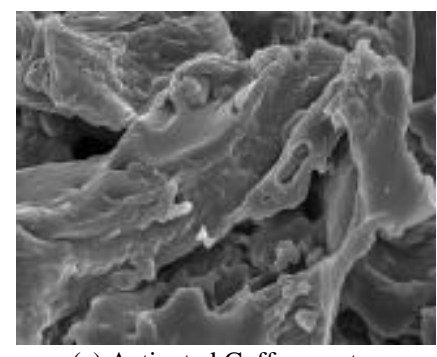

(c) Activated Coffee wastes

Fig. 3. Changes of coffee waste pore,

[Source: Department of Environmental Engineering, Daejeon University, Adsorption Characteristics of H2S on adsorbent Made by Coffee Waste, Jung-Hwan Kim, Yun-Seong Kang, Jae-Min Woo, Yeong-Seong Park, 2015]

Accordingly, it is proposed that coffee wastes have more efficiency and applicability to other substances by using coffee wastes based on precedent studies and it can be utilized for studies on manufacture method of activated carbon.

\section{RESULTS}

As constant economic development and the standard of living has been increased, desires for friendly environment has also been increased, however the social problem related to the odor has been increased day by day. Particularly, the facilities emitting odor are located around school zone and residential areas including environmental foundational facilities, therefore it is very sensible areas for odor problems. Current status of odor emitting facilities that are mostly related to civil complaints indicated that the emission concentration of Acetaldehyde was highly detected. As we investigated on current status of domestic coffee wastes in order to utilize it, we were not able to learn in detail because the occurrence rate of coffee wastes is not digitalized. However changes on consumption of coffee have been gradually increased and the amount of consumption and occurrence amount of coffee wastes are proportional. In addition, we were able to confirm that the efficiency was great in a liquid state or gas substances when coffee grounds were made by activated carbon which we referred to the references using coffee wastes.

\section{CONCLUSIONS}

To solve the odor problems, there are many people who attempt to solve, however it is not easy to solve the fundamental reason of the odor. In the odor emitting facility, sealing function has been improved in order to control the odor and the minimum concentration is emitted through the processing process. However, the local residents are constantly bringing up a civil complaint in the spite of the attempts. On the other hands, the odor control is not being maintained due to many reasons in the site. Economic reasons cannot be excluded. The fundamental adsorption facilities must have changed the old absorbents into the new absorbents regularly however it has been not maintained. Therefore, we applied to the activated carbon of coffee wastes into odor processing in order to find efficient and economic absorbents. We were able to find verification of 
efficiency on adsorptive power of activated carbon of coffee wastes through the precedent studies. The biggest benefit of coffee wastes is easily found in coffee shops therefore it is economic. In addition, thrown coffee wastes can be recycled and it is regarded as positive aspect. Accordingly we will measure processing efficiency the odor substance Acetaldehyde which is the odor problem around school zone by making activated carbon of coffee wastes in future studies and it is expected to have high efficiency based on the findings of research.

\section{ACKNOWLEDGEMENT}

"This Paper is financially supported by Korea Ministry of Environment (MOE) as Knowledge-based environmental services Human resource development project."

\section{REFERENCES}

[1] Department of Atmosphere preservation of Incheon Metropolitan City, Namdong Area Odor Improvement Council, p. 6, June 2016.

[2] H. J. Jung, Coffee \& Greenhouse Gas, and Climate Change, Sungshin Women's University, March 2014

[3] Korea Ministry of Environment (MOE), Coffee Grounds are Waste, Collecting Is Grow the Crop, pp. 1-2, April 2016.

[4] Department of Atmosphere preservation of Incheon Metropolitan City, Namdong Area Odor Improvement Council, pp. 17-32, Jun 2016.

[5] tat.me.go.kr. [Online]. Available: http://stat.me.go.kr

[6] Seul-Gi Kim, Seung-Min Na, and Young-Gyu Son, "Evaluation of the adsorptive capacity of spent coffee powder for the removal of aqueous organic pollutants," Journal of Wetlands Research, vol. 18, no. 1, pp. 39-44, February 2016.

[7] Jung-Hwan Kim, Yun-Seong Kang, Jae-Min Woo, and Yeong-Seong Park, Adsorption Characteristics of $\mathrm{H}_{2} \mathrm{~S}$ on Adsorbent Made by Coffee Waste, Environment Problem Research of Daejeon University, vol. 19, pp. 33-38, 2015.

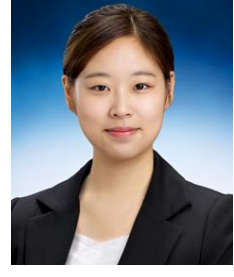

Eun Ji Woo was born in Republic of Korea on $14^{\text {th }}$ March 1992. She attends in the master's course of Dept. of Environment and Energy Engineering in Graduate School of Incheon National University.

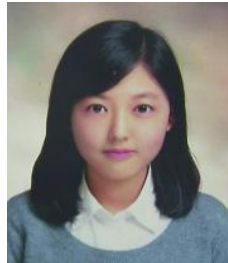

Yu Jin Oh was born in Republic of Korea on 23th Octorber 1995. She attends in course of the Bachelor Dept. of Environmental Health in Korea National Open University.

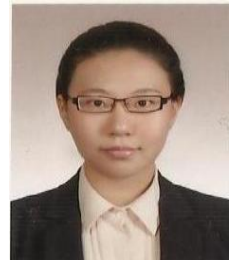

Ji Ye Yoo graduated from Incheon National University, and got the master degrees in same university. Her major fields of research are the air pollution control, greenhouse gas and odor management. She is now enrolled in a doctoral course at the Department of Climate International Cooperation, Incheon National University, Republic of Korea.

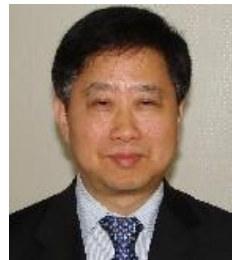

Chan Jin Park graduated from Korea University, an got the master and $\mathrm{PhD}$ degrees in same university. His major fields of research are the air pollution control, greenhouse gas technology and odor management technology. His another interest is green growth policy. He is now full-professor in Incheon National University at Urban and Environmental Engineering School. 